Published in final edited form as:

Schizophr Res. 2013 May ; 146(0): 289-290. doi:10.1016/j.schres.2013.02.021.

\title{
Comprehensive Analysis of Copy Number Variation in Monozygotic Twins Discordant for Bipolar Disorder or Schizophrenia
}

\author{
Rachael J. Bloom ${ }^{1}$, Anna K Kähler ${ }^{1,2,3}$, Ann L. Collins ${ }^{1}$, Guanhua Chen ${ }^{4}$, Tyrone D. \\ Cannon $^{5}$, Christina Hultman ${ }^{2, \dagger}$, and Patrick F. Sullivan ${ }^{1,2,6, \dagger}$ \\ ${ }^{1}$ Department of Genetics, University of North Carolina at Chapel Hill, Chapel Hill, NC, USA \\ ${ }^{2}$ Department of Medical Epidemiology and Biostatistics, Karolinska Institutet, Stockholm, Sweden \\ ${ }^{3}$ Department of Psychiatry, Oslo University Hospital - Ulleval, Oslo, Norway \\ ${ }^{4}$ Department of Biostatistics University of North Carolina at Chapel Hill, Chapel Hill, NC, USA \\ ${ }^{5}$ Departments of Psychology and Psychiatry, Yale University, New Haven, CT, USA \\ ${ }^{6}$ Department of Psychiatry, University of North Carolina at Chapel Hill, Chapel Hill, NC, USA
}

\begin{abstract}
Copy number variation plays a clear role in the etiology of many psychiatric disorders, particularly schizophrenia. We performed array-CGH to look for copy number variants between five pairs of monozygotic twins discordant for bipolar disorder or schizophrenia. Our study found no differences in copy number variants between the sets of twins. Although alluring, realistic accounting for heterogeneity and chimerism highlight the technological limitations in studying monozygotic twins discordant for psychiatric disorders.
\end{abstract}

\section{Keywords}

schizophrenia; bipolar disorder; monozygotic twin; discordant; genetics; copy number variation; structural variation

(C) 2012 Elsevier B.V. All rights reserved.

Correspond with Dr Sullivan: Department of Genetics, CB\#7264, 5097 Genomic Medicine, University of North Carolina, Chapel Hill, NC, 27599-7264, USA. Voice: +919-966-3358, FAX: +919-966-3630, pfsulliv@med.unc.edu.

†equivalent contributions

Publisher's Disclaimer: This is a PDF file of an unedited manuscript that has been accepted for publication. As a service to our customers we are providing this early version of the manuscript. The manuscript will undergo copyediting, typesetting, and review of the resulting proof before it is published in its final citable form. Please note that during the production process errors may be discovered which could affect the content, and all legal disclaimers that apply to the journal pertain.

Author Contributions

RJB performed the experiments and analysis and wrote paper. AKK and ALC helped design the experiment and interpret the results. GC conducted statistical analyses. TDC and $\mathrm{CH}$ designed and implemented the parent study. PFS designed the study and obtained funding. All authors reviewed and approved the final manuscript.

Conflicts of InTERest

Dr Sullivan was on the SAB of Expression Analysis, Durham, NC. The other authors report no conflicts. 


\section{Introduction}

Schizophrenia and bipolar disorder have a concordance rate of about $50 \%$ in monozygotic twins, suggesting that both genetic and environmental factors contribute to the etiology of these psychiatric disorders.(Smoller and Finn, 2003; Sullivan et al., 2003) Copy number variants $(\mathrm{CNVs})$ are an important class of genetic variation, and play a clear role in the etiology of many psychiatric disorders, particularly schizophrenia.(Sullivan et al., 2012) In this study, we analyzed CNV differences between monozygotic twins rigorously discordant for a psychotic disorder to attempt to identify CNVs that arose mitotically after zygote separation that might be responsible for phenotypic differences.

\section{Methods}

Full methods are in the Supplementary Materials. All protocols were reviewed and approved by Ethical Committees in Sweden and the US, and all subjects provided written informed consent. Briefly, using the population-based Swedish Twin Register(Lichtenstein et al., 2006), we ascertained and directly evaluated five pairs of monozygotic twins where one twin met DSM-IV criteria for schizophrenia, schizoaffective disorder, or bipolar disorder and the cotwin had never met criteria for any psychotic disorder (Table S1). We further required that $\geq 10$ years had passed since disease onset in the affected twin in order to minimize the effect of variable age of onset. Monozygosity was confirmed by genotyping a panel of 47 SNPs.(Hannelius et al., 2007) We analyzed DNA samples obtained from whole blood using Roche Nimblegen 2.1M probe comparative genomic hybridization $(\mathrm{CGH})$ arrays, with a median probe spacing of 1,169 bp, in theory sufficient for genome-wide detection of CNVs to $\sim 20 \mathrm{~Kb}$ resolution. To enhance specificity, we used the dual-color array to hybridize the affected twin against the unaffected twin. Final CNV call sets were generated using NimbleScan (v2.6) with default settings. We removed segments with $\log _{2}$ ratios from -0.26 to 0.22 because, under idealized assumptions, these limits are needed to detect one copy gains or one copy losses present in at least one-third of the cells in the affected twin (Table S2). All predicted calls were annotated for intersections with genome gaps (telomeres and centromeres with low probe coverage can confound CNV calling algorithms), segmental duplications, genes, and CNVs implicated in psychiatric disorders. (Sullivan et al., 2012)

\section{Results}

There was a clear effect of array quality on the number of calls that were predicted. For our chosen $\log _{2}$ ratio thresholds (Table S3). Using these $\log _{2}$ ratio thresholds, each pair had an average of 36 calls, with the number of calls ranging from 2 (Pairs 1 and 5) to 74 (Pair 3). We found no calls spanning gap regions. A few predicted calls overlapped with large ( $>1$ $\mathrm{Mb}$ ) CNVs previously implicated in schizophrenia, but all of the predicted CNVs were small $(<50 \mathrm{~Kb})$ and overlapped very small proportions of these large CNVs (Table S4). Of the 186 predicted calls, 67 contained genes. We visually reviewed all predicted calls but none had clear breakpoints indicative of a true CNV but rather represented genomic "waviness" consistent with normal variation and noise in aCGH. One pair appeared to have a duplication of the entire transcript of $S V 2 A$ (synaptic vesicle glycoprotein 2). We attempted to verify this putative $\mathrm{CNV}$ using qPCR, but both twins appeared to be copy number two, suggesting a false positive aCGH CNV call (Figure S1).

\section{Discussion}

Monozygotic twins discordant for disease have been the focus of many genetic and epigenetic studies.(Baranzini et al., 2010; Bruder et al., 2008; Maiti et al., 2011; Ono et al., 
2010) As aCGH data have high-false positive and false-negative rates due to data quality, analysis methods, and other factors, (Scherer et al., 2007) we attempted to minimize the impact of these factors with a rigorous set of manual and automated filters. Prior studies that reported de novo CNVs discordant between $\mathrm{MZ}$ twins were discovered via comparison to other family members(Maiti et al., 2011) yet, to our knowledge, no prior study has hybridized MZ twins to each other. Other studies comparing genetic and epigenetic differences between MZ twins discordant for disease found no evidence of differences that could explain disease discordance.(Baranzini et al., 2010) Moreover, somatic mutations can be mosaic within an individual, and an etiologically important CNV present in brain might not be found in peripheral blood. (Bruder et al., 2008)

In choosing to hybridize the affected to the unaffected twin, we made several explicit assumptions. First, we attempted to maximize our chance of detection by directly searching for a CNV difference arising mitotically. Here, phenotypic discordance between MZ twins is caused by a CNV present in the affected twin under a direct and parsimonious genetic model. It is possible that the true model is more complex. Given our hybridization choice, we would have missed detecting a germline $\mathrm{CNV}$ present in both the affected and unaffected co-twin. This could have been important if, for example, a CNV is predisposing but requires an environmental exposure to trigger the development of a psychotic disorder. Second, we had DNA from a single tissue (peripheral blood). While we attempted to allow for mosaicism, a causal CNV arising mitotically during development might exist only in a part of the brain and be absent in peripheral blood. Somatic mutations in the brains of individuals with hemimegalencephaly but not in peripheral blood have been described. (Poduri et al., 2012)

In summary, we were unable to identify mitotic CNVs in peripheral blood that are candidate loci for phenotypic discordance between $\mathrm{MZ}$ twins rigorously discordant for psychotic disorders. This work should be considered in light of two limitations. First, although we used a high-resolution aCGH platform, we still might have missed etiologically important CNVs that were present in other tissues but not peripheral blood, not detectible by the technology we used, or which present in a small fraction of cells. Second, our sample size was small, and we cannot exclude the possibility of the existence of etiologically important mitotic CNVs in schizophrenia. However, it is unlikely that large CNVs $(>500 \mathrm{~Kb})$ were present in a large fraction of the somatic cells we studied, and we note that the offspring of MZ twins discordant for schizophrenia appear to have similar risks for schizophrenia an observation probably consistent with our negative results (Kringlen and Cramer, 1989).

MZ twins rigorously discordant for psychosis represent a unique and compelling opportunity to search for causal genetic differences, but more conclusive study will require improved technological resolution and direct access to alternative tissues. Under some genetic models, we note that this can be a challenging task for current genomic technologies (e.g., identifying a single causal base pair change in a six billion base pair diploid genome present in a localized portion of the brain).

\title{
Supplementary Material
}

Refer to Web version on PubMed Central for supplementary material.

\section{Acknowledgments}

\author{
Role of the Funding Source \\ Funding for this project was from a NARSAD Distinguished Investigator award (Sullivan) the NIMH (MH052857, \\ Cannon). The funders had no role in the design, execution, analysis, and manuscript preparation.
}


Funding for this project was from a NARSAD Distinguished Investigator award (Sullivan) the NIMH (MH052857, Cannon). The funders had no role in the design, execution, analysis, and manuscript preparation.

\section{References}

Baranzini SE, Mudge J, van Velkinburgh JC, Khankhanian P, Khrebtukova I, Miller NA, Zhang L, Farmer AD, Bell CJ, Kim RW, May GD, Woodward JE, Caillier SJ, McElroy JP, Gomez R, Pando MJ, Clendenen LE, Ganusova EE, Schilkey FD, Ramaraj T, Khan OA, Huntley JJ, Luo S, Kwok PY, Wu TD, Schroth GP, Oksenberg JR, Hauser SL, Kingsmore SF. Genome, epigenome and RNA sequences of monozygotic twins discordant for multiple sclerosis. Nature. 2010; 464(7293):13511356. [PubMed: 20428171]

Bruder CE, Piotrowski A, Gijsbers AA, Andersson R, Erickson S, Diaz de Stahl T, Menzel U, Sandgren J, von Tell D, Poplawski A, Crowley M, Crasto C, Partridge EC, Tiwari H, Allison DB, Komorowski J, van Ommen GJ, Boomsma DI, Pedersen NL, den Dunnen JT, Wirdefeldt K, Dumanski JP. Phenotypically concordant and discordant monozygotic twins display different DNA copy-numbervariation profiles. Am J Hum Genet. 2008; 82(3):763-771. [PubMed: 18304490]

Hannelius U, Gherman L, Makela VV, Lindstedt A, Zucchelli M, Lagerberg C, Tybring G, Kere J, Lindgren CM. Large-scale zygosity testing using single nucleotide polymorphisms. Twin Res Hum Genet. 2007; 10(4):604-625. [PubMed: 17708702]

Kringlen E, Cramer G. Offspring of monozygotic twins discordant for schizophrenia. Arch Gen Psychiatry. 1989; 46(10):873-877. [PubMed: 2802926]

Lichtenstein P, Sullivan PF, Cnattingius S, Gatz M, Johansson S, Carlstrom E, Bjork C, Svartengren M, Wolk A, Klareskog L, de Faire U, Schalling M, Palmgren J, Pedersen NL. The Swedish Twin Registry in the third millennium: an update. Twin Res Hum Genet. 2006; 9(6):875-882. [PubMed: 17254424]

Maiti S, Kumar KH, Castellani CA, O'Reilly R, Singh SM. Ontogenetic de novo copy number variations (CNVs) as a source of genetic individuality: studies on two families with MZD twins for schizophrenia. PLoS One. 2011; 6(3):e17125. [PubMed: 21399695]

Ono S, Imamura A, Tasaki S, Kurotaki N, Ozawa H, Yoshiura K, Okazaki Y. Failure to confirm CNVs as of aetiological significance in twin pairs discordant for schizophrenia. Twin Res Hum Genet. 2010; 13(5):455-460. [PubMed: 20874467]

Poduri A, Evrony GD, Cai X, Elhosary PC, Beroukhim R, Lehtinen MK, Hills LB, Heinzen EL, Hill A, Hill RS, Barry BJ, Bourgeois BF, Riviello JJ, Barkovich AJ, Black PM, Ligon KL, Walsh CA. Somatic activation of AKT3 causes hemispheric developmental brain malformations. Neuron. 2012; 74(1):41-48. [PubMed: 22500628]

Scherer SW, Lee C, Birney E, Altshuler DM, Eichler EE, Carter NP, Hurles ME, Feuk L. Challenges and standards in integrating surveys of structural variation. Nat Genet. 2007; 39(7 Suppl):S7-S15. [PubMed: 17597783]

Smoller JW, Finn CT. Family, twin, and adoption studies of bipolar disorder. Am J Med Genet C Semin Med Genet. 2003; 123C(1):48-58. [PubMed: 14601036]

Sullivan PF, Daly MJ, O'Donovan M. Genetic architectures of psychiatric disorders: the emerging picture and its implications. Nat Rev Genet. 2012; 13(8):537-551. [PubMed: 22777127]

Sullivan PF, Kendler KS, Neale MC. Schizophrenia as a complex trait: evidence from a meta-analysis of twin studies. Arch Gen Psychiatry. 2003; 60(12):1187-1192. [PubMed: 14662550] 